\title{
Prevalence of Ticks Infesting Dairy Cattle and the Pathogens They Harbour in Smallholder Farms in Peri-Urban Areas of Nairobi, Kenya
}

\author{
Shepelo Getrude Peter $\left(\mathbb{D},{ }^{1}\right.$ Hellen Wambui Kariuki $\left(\mathbb{D},{ }^{2}\right.$ Gabriel Oluga Aboge ${ }^{(D},{ }^{3}$ \\ Daniel Waweru Gakuya $\left(\mathbb{D},{ }^{1}\right.$ Ndichu Maingi $\left(\mathbb{D}^{4},{ }^{4}\right.$ and Charles Matiku Mulei $\left(\mathbb{C}^{1}\right.$ \\ ${ }^{1}$ Department of Clinical Studies, Faculty of Veterinary Medicine, University of Nairobi, P.O. Box 29053-00625, Nairobi, Kenya \\ ${ }^{2}$ Department of Microbiology, Faculty of Health Sciences, University of Nairobi, P.O. Box 19676-00202, Nairobi, Kenya \\ ${ }^{3}$ Department of Public Health Pharmacology and Toxicology, Faculty of Veterinary Medicine, University of Nairobi, \\ P.O. Box 29053-00625, Nairobi, Kenya \\ ${ }^{4}$ Department of Veterinary Pathology, Microbiology and Parasitology, Faculty of Veterinary Medicine, University of Nairobi, \\ P.O. Box 29053-00625, Nairobi, Kenya
}

Correspondence should be addressed to Shepelo Getrude Peter; shepelo@uonbi.ac.ke

Received 22 July 2021; Accepted 19 November 2021; Published 10 December 2021

Academic Editor: Nora Mestorino

Copyright ( 2021 Shepelo Getrude Peter et al. This is an open access article distributed under the Creative Commons Attribution License, which permits unrestricted use, distribution, and reproduction in any medium, provided the original work is properly cited.

\begin{abstract}
This study aimed at determining the tick species infesting dairy cattle in Nairobi, Kenya, and the pathogens they harbour. While ticks are well-known vectors of major bacterial pathogens of both veterinary importance and public health importance, few studies have investigated the range of the tick species and the associated pathogens, especially present in unique dairy production systems, which compromise animal welfare, such as those in peri-urban areas. A cross-sectional study was undertaken involving 314 randomly selected dairy cattle in 109 smallholder farms. Each animal was examined for attached ticks followed by morphological tick identification at the species level. Genomic DNA was extracted from each of the ticks, and 16S rDNA gene was amplified for pathogen identification. Sequencing of the amplicons and subsequent BLASTn analysis, multiple sequence alignment, and phylogenetic reconstruction were performed to confirm the species of the pathogens. Sixty-six (21.0\%) of the cattle examined had ticks. A total of 94 adult ticks were found on the cattle, and of these, 63 (67.0\%), 18 (19.1\%), and $13(13.8 \%)$ were in the genera Rhipicephalus, Amblyomma, and Hyalomma, respectively. Twelve tick species in Rhipicephalus genus and two in Amblyomma and Hyalomma genera were identified. Although $R h$. decoloratus was the most prevalent tick (24.5\% (23/94)), the emerging $R h$. microplus $(6.4 \%(6 / 94))$ was also identified. The DNA of Rickettsia was detected in the ticks, with Rickettsia conorii in H. rufipes and A. variegatum, and Rickettsia aeschlimannii in Rh. microplus and H. rufipes, while Ehrlichia ruminantium and E. canis were in A. variegatum. In conclusion, the study reported a wide range of tick species present in the study area including Rhipicephalus microplus, which is an emerging tick species in parts of Kenya. The ticks harboured DNA of Rickettsia and Ehrlichia, highlighting possible animal and human health concerns. Hence, effective tick control strategies remain paramount to prevent potential diseases associated with the harboured pathogens.
\end{abstract}

\section{Introduction}

Ticks are important vectors for diseases of both veterinary and public health concerns. They are only second to mosquitoes in the transmission of animal and human pathogens [1]. They are known to transmit various pathogens including bacteria, rickettsia, protozoa, and viruses that are economically important to livestock [2] and those of zoonotic potential $[3,4]$. In addition to the transmission of pathogens, they can cause tick worry and toxic reactions to animals [5]. The occurrence of the tick-borne diseases is related to the spatial distribution of the respective tick vectors [6]. The 
inevitable climate change, increase in human population, and constantly evolving changes in land-use patterns and livestock husbandry practices in Kenya are some of the reasons that have led to variations in the epidemiology and diversity of tick-borne diseases $[7,8]$. There are limited studies in Kenya that have identified the tick species present and the pathogens they harbour. Such studies have mainly focused on pastoral areas $[9,10]$ and livestock-wildlife interfaces $[11,12]$ with hardly any focus on ticks present in unique production systems such as those in peri-urban areas of Nairobi.

Dairy cattle rearing is a common practice in the periurban areas of Nairobi County, Kenya, where they have been established to meet the ever-increasing milk consumption by the city's population of nearly 4.3 million people [13]. These production systems are characterized by substandard animal husbandry practices, which compromise animal welfare $[14,15]$. The substandard animal husbandry practices are mainly a consequence of extensive land subdivision in periurban areas of the city resulting in small land sizes for cattle housing and minimal spaces for growing fodder [16]. Compromised animal welfare has been associated with decreased immunity, thereby predisposing animals to diseases [17]. Due to the land subdivision, the grasses and fodder for cattle in these production systems are sourced from various regions of the country with the risk of introducing a wide range of tick species to the animals.

A recent report by Peter et al. [18] indicated the infection of cattle with various tick-borne pathogens in these periurban areas of Nairobi. This study was carried out to further identify ticks found attached to those cattle and screen them for Anaplasma, Ehrlichia, and Rickettsia pathogens. Understanding the tick species in a given region has been used as a guide in preempting disease conditions to expect [19]. This information is therefore important in guiding tick control programs, hence preventing outbreaks of associated diseases.

\section{Materials and Methods}

2.1. Ethical Approval. This study was approved by the Biosecurity, Animal Use and Ethics Committee (BAUEC) of the Faculty of Veterinary Medicine, University of Nairobi, Kenya (FVM BAUEC/2016/122). Appropriate physical restrain of the cattle in a crush was done during the collection of the ticks to ensure that the animal did not struggle and all other animal welfare concerns were keenly adhered to. After a detailed explanation of the study to the animal owners, verbal consent was sort before recruiting the animals to the study.

2.2. Study Area. The study was carried out in peri-urban areas of Nairobi City County as previously described [20], and the method description partially reproduces the wording. Nairobi City, which is the capital of Kenya, is situated in this county. The county lies at 1.28333 latitude and 36.81667 longitude and $1795 \mathrm{~m}$ above sea level and consists of 17 subcounties, the highest number of administrative units in a single county in Kenya. For purposes of data collection, the county was mapped into four quadrants taking the central business district (CBD) as the center. In each of the quadrants, the subcounty with the highest cattle population was purposively selected. Therefore, the subcounties identified were Westlands (north quadrant), Kasarani (east quadrant), Lang'ata (south quadrant), and Dagoretti (west quadrant).

2.3. Study Design. This was a cross-sectional study conducted between January and May 2017 where dairy cattle recruited for a previous study [18] were examined for ticks on their various body parts. Within the subcounties, the databases kept by the subcounty veterinary officers were used as the sampling frames for random selection of farms in the study. Random sampling was used at the farm level to identify cattle that were included in the study. A total of 314 cattle in 109 dairy farms were recruited in the study. Each animal was restrained in a crush and physically examined for the presence of ticks on the head, ears, neck, dewlap, flanks, ventral abdomen, and perineal areas.

2.4. Tick Collection and Morphological Identification. All ticks found attached to the cattle were picked using forceps taking precautions not to break the mouthparts. They were stored in labelled containers containing 70\% alcohol before transportation to the Parasitology Laboratory in the Department of Veterinary Pathology, Microbiology and Parasitology, University of Nairobi. Morphological identification of ticks was done to the species level based on taxonomic keys such as colour, shape, and size of capitulum, eyes, presence or absence of festoons, punctuation, groove on the scutum or conscutum, and presence or absence of adanal shield as described by Walker et al. [21] using a binocular microscope. Each identified tick was stored in a separate labelled collection tube containing $70 \%$ alcohol.

2.5. DNA Extraction from Ticks. The ticks were removed from the 70\% alcohol, air-dried, and rinsed twice in distilled water before being dried on a filter paper. Genomic DNA was extracted from ticks using the DNeasy Blood and Tissue Kit (Qiagen, Hilden, Germany) following the manufacturer's instructions. DNA extraction was undertaken only on unengorged ticks to avoid PCR inhibition from excess erythrocytes as recommended by Silaghi et al. [22] and avoid confusion with DNA from the tick blood meal. The quality of the DNA was verified using QIAxpert slides in the QIAxpert machine (Qiagen, Hilden, Germany), and the integrity was confirmed by running $5 \mu \mathrm{l}$ of the eluted DNA using $1 \%$ agarose gel (Sigma, USA). The DNA was stored at $-20^{\circ} \mathrm{C}$ awaiting analysis.

2.6. Polymerase Chain Reaction (PCR) Amplification and Sequencing of Pathogens'DNA in the Ticks. Polymerase chain reaction was performed on $16 \mathrm{~S}$ rDNA gene using previously described primers and protocol [18]. For Anaplasma species, the forward primer ANAF 5'-TAGTGGCAGACGG 
GTGAGTA- $3^{\prime}$ and a reverse primer ANAR $5^{\prime}$-AATTCCGAACAACGCTTGCC- $3^{\prime}$ were used to yield an approximately $424 \mathrm{bp}$ band, while for Ehrlichia species a forward primer EHRF $5^{\prime}$-AGCTGGTCTGAGAGGACGAT-3' and a reverse primer EHRR 5'-GAGTGCCCAGCATTACCTGT$3^{\prime}$ targeting an approximately $838 \mathrm{bp}$ of the $16 \mathrm{~S}$ rDNA were used. Double-distilled water was used as the negative control. The PCR amplification reactions were performed in a thermal cycler (Applied Biosystems Veriti 96-Well Thermal Cycler, Thermo Fisher). The amplified products were electrophoresed using $1.5 \%$ agarose gel in Tris-borate-EDTA (TBE) buffer, $\mathrm{pH} 8$, stained with ethidium bromide, and visualized using UV illuminator (UVP GelMax ${ }^{\circledR} 125$ Imager, USA). The sizes of the amplicons were determined using molecular ladder (GelPilot 1kb Plus Ladder (100), Qiagen, Germany). The resulting PCR amplicons were purified and Sanger sequenced at Macrogen Europe Laboratories (Amsterdam, the Netherlands) using the same forward and reverse primers as for the PCRs. The obtained sequences were viewed and manually verified using chromatogram peaks, edited, and assembled using CLC Main Workbench 6.8.3 Software (CLC Bio, Qiagen GmbH, Germany).

2.7. DNA Sequence Analysis. The sequences obtained from the 16S rDNA gene were analysed using Basic Local Alignment Search Tool Nucleotide (BLASTn), multiple sequence alignment (MSA), and phylogenetic reconstruction. BLASTn was used to confirm the sequence identities, while MSA and phylogenetic reconstruction identified the relationship between the study isolates and those from other regions of the world. Multiple sequence alignment was done using Log-Expectation (MUSCLE) v3.8.31 [23]. Sequence similarity was calculated using Clustal Omega to obtain identity matrix [24]. A phylogenetic reconstruction was done using MEGA 6.0 [25]. The evolutionary history was inferred using the maximum-likelihood method based on the Tamura-Nei model [26]. Initial trees for the heuristic search were obtained automatically by applying the neighbor-joining and BioNJ algorithms to a matrix of pairwise distances estimated using the maximum composite likelihood (MCL) approach and then selecting the topology with superior log-likelihood value. All positions containing gaps and missing data were eliminated. The percentage of replicate trees in which the associated taxa clustered together in the bootstrap test (1000 replicates) was shown next to the branches [27].

\section{Results}

3.1. Morphological Identification of Ticks. Of the 314 animals examined, $21.0 \%(66 / 314)$ were found to be infested with one or more ticks. A total of 118 adult ticks were found attached to the cattle at the time of sampling, but 24 were engorged; therefore, only 94 ticks were analysed further. Among the ticks analysed, twelve tick species in the three genera Rhipicephalus (Rh.), Amblyomma (A.), and Hyalomma (H.) were identified (Table 1). The majority (67\% (63/94)) of them were Rhipicephalus species, while Hyalomma species were
TABLE 1: Distribution of the tick species identified from dairy cattle in peri-urban areas of Nairobi, Kenya.

\begin{tabular}{lc}
\hline Tick species & No. of ticks collected $(\%, n=94)$ \\
\hline Rhipicephalus (Rh.) species & \\
Rh. (boophilus) decoloratus & $23(24.5)$ \\
Rh. evertsi evertsi & $11(11.7)$ \\
Rh. pulchellus & $11(11.7)$ \\
Rh. (boophilus) microplus & $6(6.4)$ \\
Rh. sanguineous & $5(5.3)$ \\
Rh. simus & $3(3.2)$ \\
Rh. appendiculatus & $3(3.2)$ \\
Rh. praetextatus & $1(1.2)$ \\
Amblyomma (A.) species & \\
A. variegatum & $15(15.6)$ \\
A. gemma & $3(3.2)$ \\
Hyalomma (H.) species & \\
H. rufipes & $8(8.5)$ \\
H. truncatum & $5(5.3)$ \\
Total & $\mathbf{9 4}(\mathbf{1 0 0})$ \\
\hline
\end{tabular}

the least (13.8\% (13/94)). In Rhipicephalus genera, $R h .(b)$. decoloratus was the most prevalent tick species and only one tick was identified as $R h$. praetextatus. Rhipicephalus (boophilus) microplus was also identified in 6\% (6/94) of the examined ticks. Amblyomma variegatum and Hyalomma rufipes were the most prevalent in their respective genera. All the tick species were only found in cattle from Kasarani Subcounty.

\subsection{Pathogen DNA Detected from Ticks Infesting Dairy Cattle} in Smallholder Farms in Peri-urban Areas of Nairobi. Using primers previously used by Peter et al. [18] to detect Anaplasma species, 25.6\% (24/94) of the samples yielded the expected PCR bands at approximately $424 \mathrm{bp}$. Eight representative amplicons were selected for sequencing. On BLASTn analysis, seven of them had DNA of Rickettsia and one Anaplasma ovis (Table 2).

The DNA of Anaplasma ovis was detected in Rh. evertsi evertsi tick, while all the three tick genera were found to harbour DNA of Rickettsia species. The DNA of Rickettsia aeschlimannii was detected in Rh. (boophilus) microplus and Hyalomma rufipes ticks. On the other hand, the DNA of Ri. conorii was detected in Amblyomma gemma and A. variegatum (Table 2). Rickettsia conorii was detected in $62.5 \%(5 / 8)$ of the sequenced amplicons, indicating sequence similarity of between $98.30 \%$ and $99.38 \%$. Rickettsia aeschlimannii was confirmed in two of the sequenced amplicons $(25 \%(2 / 8))$ with a sequence similarity of between 99.30\% and $99.76 \%$ (Table 2).

On analysis using primers for the detection of Ehrlichia species, of the 94 ticks that were analysed, 8.5\% (8/94) were positive yielding PCR bands at approximately $838 \mathrm{bp}$. Five representative samples were sequenced for the detection of the pathogens. Three of the sequences, one from $R h$. (boophilus) decoloratus and two from A. variegatum, were similar to Ehrlichia canis with a sequence identity of 99.76 to $100 \%$ (Table 3). One isolate from A. variegatum was $100 \%$ 
TABle 2: Pathogens' DNA detected from ticks collected from dairy cattle in peri-urban areas of Nairobi, Kenya.

\begin{tabular}{|c|c|c|c|c|c|}
\hline Isolate & $\begin{array}{l}\text { Accession no. (this } \\
\text { study) }\end{array}$ & Tick species & $\begin{array}{l}\text { Accession no. of highest BLASTn } \\
\text { match }\end{array}$ & $\begin{array}{c}\text { Pathogen DNA } \\
\text { detected }\end{array}$ & $\%$ identity \\
\hline $522 \mathrm{~A}$ & MT366207 & Rh. evertsi evertsi & MG869525.1 & Anaplasma ovis & 99.77 \\
\hline $281 \mathrm{C}$ & MT366164 & $\begin{array}{l}\text { Rh. (boophilus) } \\
\text { microplus }\end{array}$ & HM050274.1 & Ri. aeschlimannii & 99.76 \\
\hline $290 \mathrm{~B}$ & MT366165 & H. rufipes & HM050274.1 & Ri. aeschlimannii & 99.30 \\
\hline $286 \mathrm{~A}$ & MT366066 & A. gemma & MG564259.1 & Ri. conorii & 98.38 \\
\hline $524 \mathrm{~A}$ & MT366070 & A. variegatum & MG564259.1 & Ri. conorii & 99.30 \\
\hline $519 A$ & MT366069 & A. variegatum & MG564259.1 & Ri. conorii & 98.30 \\
\hline $501 \mathrm{~A}$ & MT366067 & A. variegatum & MG564259.1 & Ri. conorii & 99.30 \\
\hline $508 \mathrm{~B}$ & MT366068 & A. variegatum & MG564259.1 & Ri. conorii & 98.38 \\
\hline
\end{tabular}

TABLe 3: Ehrlichia species DNA detected from different tick species collected from cattle in peri-urban areas of Nairobi, Kenya.

\begin{tabular}{|c|c|c|c|c|c|}
\hline Isolate & $\begin{array}{l}\text { Accession no. (this } \\
\text { study) }\end{array}$ & Tick species & $\begin{array}{l}\text { Accession no. of highest BLASTn } \\
\text { match }\end{array}$ & $\begin{array}{c}\text { Ehrlichia spp. DNA } \\
\text { detected }\end{array}$ & $\begin{array}{c}\% \\
\text { identity }\end{array}$ \\
\hline $396 \mathrm{~B}$ & MT734401 & $\begin{array}{c}\text { Rh. (boophilus) } \\
\text { decoloratus }\end{array}$ & KY594915.1 & E. canis & 100.0 \\
\hline $508 \mathrm{~B}$ & MT734402 & A. variegatum & KX987326.1 & E. canis & 99.76 \\
\hline $524 \mathrm{~A}$ & MT734403 & A. variegatum & KX180945.1 & E. canis & 100.0 \\
\hline 524AR & MT738235 & A. variegatum & NR_074155.1 & E. ruminantium & 100.0 \\
\hline $277 \mathrm{C}$ & MT738242 & Rh. sanguineous & KX987325.1 & Unidentified Ehrlichia spp. & 100.0 \\
\hline
\end{tabular}

similar to E. ruminantium, while the other sequence from Rh. sanguineus was an unidentified Ehrlichia closely related to Ehrlichia spp. isolate KX987325 from Wuhan, China. Two Amblyomma variegatum ticks were observed to be coinfected with two pathogen DNAs each: one with Ri. conorii and $E$. canis (isolate 508B) and the other with Ri. conorii and E. ruminantium (isolate 524A) (Tables 2 and 3).

3.3. Multiple Sequence Alignments of the Rickettsia and Ehrlichia Species DNA Isolated from Ticks Infesting Dairy Cattle from Peri-Urban Areas of Nairobi. Multiple sequence alignment was done on the Ri. conorii and E. canis isolates detected from cattle in peri-urban areas of Nairobi, Kenya. The nucleotide sequences of Rickettsia conorii appeared genetically diverse with multiple nucleotide sequence polymorphisms (SNPs) (Figure 1) and nucleotide diversity of up to $4 \%$ (Table 4 ). In contrast, the nucleotide sequences for Ehrlichia canis were highly conserved.

3.4. Phylogenetic Positioning of the Rickettsia and Ehrlichia Species DNA Detected in Ticks Infesting Dairy Cattle from PeriUrban Areas of Nairobi. Phylogenetic analysis was done to confirm the DNA sequences of Rickettsia and Ehrlichia detected and identify the genetic relatedness to other isolates worldwide (Figures 2 and 3). Ri. conorii Kenyan isolates were closely related to those from the USA, China, Nigeria, and Egypt but differed from those from Zambia and Uganda. Rickettsia aeschlimannii Kenyan isolates were clustered together with an isolate from Senegal (KY229715.1) and Lebanon (HM050274.1) (Figure 2).

On the other hand, Ehrlichia canis isolates from the Kenyan ticks were closely related to dog isolates from Iraq and Turkey and a tick isolate from Uganda (Figure 3). E. ruminantium isolates from $A$. variegatum in this study were clustered together with a tick isolate from Tanzania and other isolates from cattle in South Africa and the USA. The unidentified Ehrlichia species was closely related to E. canis and E. minasensis but distantly from E. ruminantium.

3.5. Nucleotide Sequence Accession Numbers for the Pathogens Detected in the Identified Kenyan Ticks. The partial $16 \mathrm{~S}$ rDNA gene sequences obtained from pathogens in ticks from this study were deposited in the GenBank under the following accession numbers: MT366066 to MT366070 for Ri. conorii, MT366164 to MT366165 for Ri. aeschlimannii, MT366207 for Anaplasma ovis, MT734401 to MT734403 for E. canis, MT738235 for E. ruminantium, and MT738242 for the unidentified Ehrlichia species.

\section{Discussion}

Tick infestation was relatively low in the study cattle with all the ticks collected being from Kasarani Subcounty. The problem of tick infestation and consequently tick-borne diseases has been well documented as a challenge in smallholder dairy farming in peri-urban areas of Nairobi [28] and especially in Kasarani Subcounty [29]. However, the increased use of acaricide, which is a common practice in smallholder dairy farms in Kenya [30] and the dry season at the time of sampling [21], may explain the low tick infestation reported in this study.

The high tick infestation in Kasarani Subcounty has been associated with open grazing lands that attract pastoral livestock from the neighboring Kajiado County, which are often heavily infested with ticks [31]. Despite the heavy infestation, there is usually minimal impact on the health of pastoral cattle since they exhibit a certain level of resistance to tick-borne diseases [30]. However, they contaminate the grazing pastures with the ticks they carry. Since cut and carry 


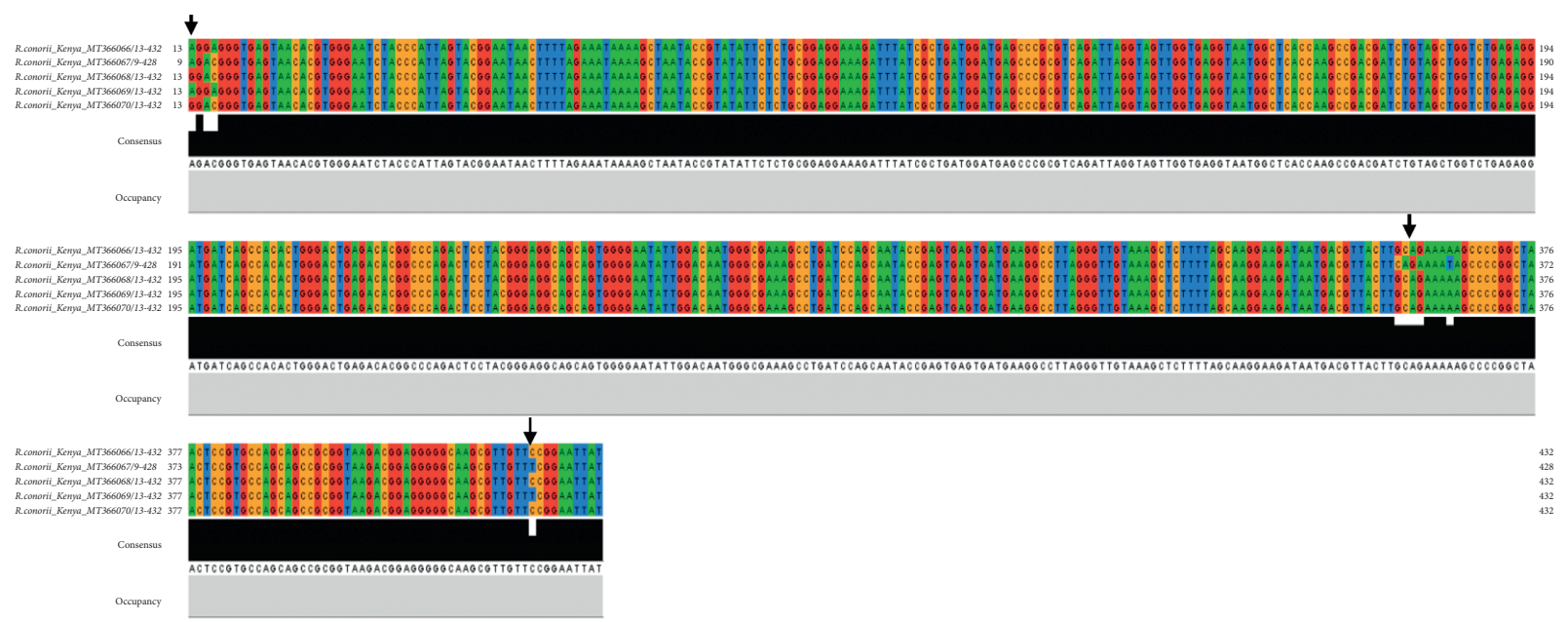

Figure 1: Multiple sequence alignment for Ri. conorii nucleotide sequences obtained from ticks infesting cattle in Nairobi, Kenya. The black arrows show regions of multiple nucleotide sequence polymorphisms (SNPs).

TABLE 4: Pairwise percent identity matches of $16 \mathrm{~S}$ rDNA sequences of Ri. conorii isolated from ticks infesting dairy cattle in Nairobi, Kenya. The numbers denote the nucleotide identity rates found between the sequences.

\begin{tabular}{lccccc}
\hline Isolate & $501 \mathrm{~A}$ & $286 \mathrm{~A}$ & $519 \mathrm{~A}$ & $508 \mathrm{~B}$ & 58.1 \\
\hline $501 \mathrm{~A}$ & 100.0 & 96.0 & 96.1 & 97.0 & 97.7 \\
$286 \mathrm{~A}$ & 96.0 & 100.0 & 99.8 & 97.2 & 96.8 \\
$519 \mathrm{~A}$ & 96.1 & 99.8 & 100.0 & 100.0 & 96.2 \\
$508 \mathrm{~B}$ & 98.1 & 97.0 & 97.2 & 99.8 & 99.8 \\
$524 \mathrm{~A}$ & 97.7 & 96.8 & 96.2 & 100.0 \\
\hline
\end{tabular}

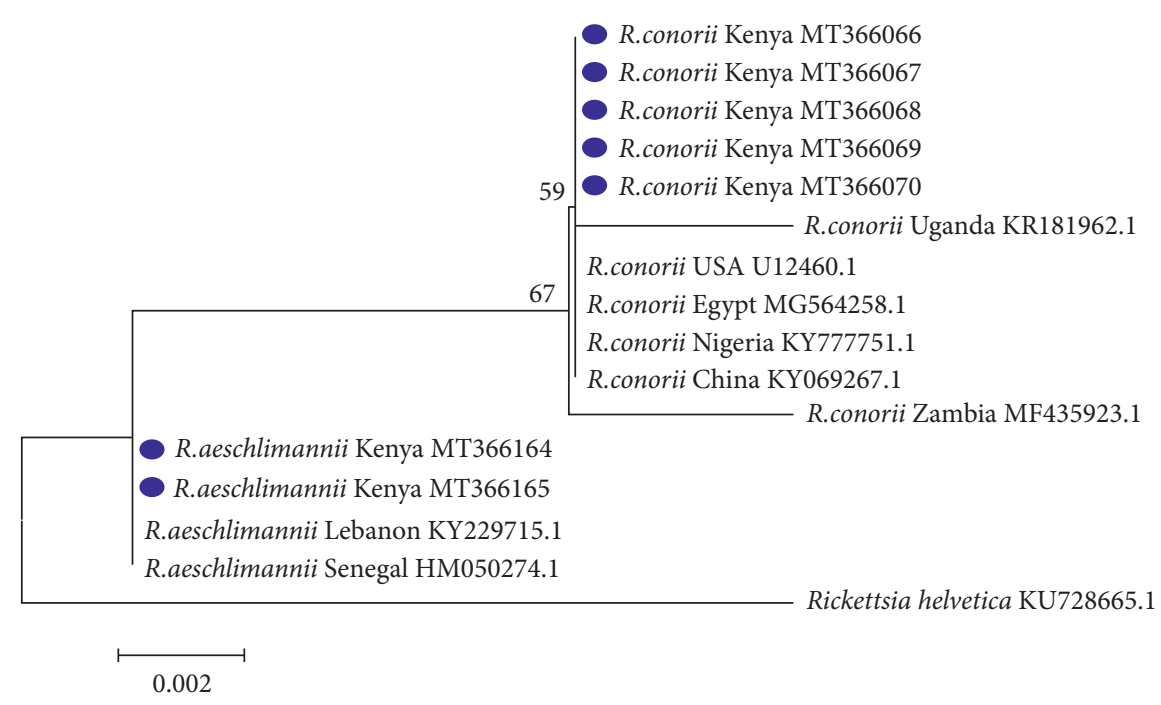

FIGURE 2: Maximum-likelihood tree of Rickettsia spp. reconstructed based on partial sequences of 16S rDNA gene with 1000 bootstrap replicates. The analysis involved 16 nucleotide sequences with seven from this study and nine others obtained from the GenBank. The tree indicates the phylogenetic relatedness of Rickettsia isolates obtained from ticks infesting cattle in peri-urban areas of Nairobi, Kenya, marked with blue dot and sequences from other countries. Rickettsia helvetica was used as an out-group. Sequence accession numbers are given at the end of each isolate.

of fodder from the roadsides is the common method of feeding livestock in this area $[16,32]$, the ticks are simultaneously carried to the zero-grazed cattle.

Ticks in the genera Rhipicephalus including subgenera boophilus, Amblyomma, and Hyalomma were identified in this study. Ticks in these three genera have been previously reported in Kenya [33], Tanzania [34], Uganda [35], and Ethiopia [36]. The wide range of species identified in this study may have been influenced by the conducive climatic conditions that support tick vectors $[4,7]$. Ticks in these 


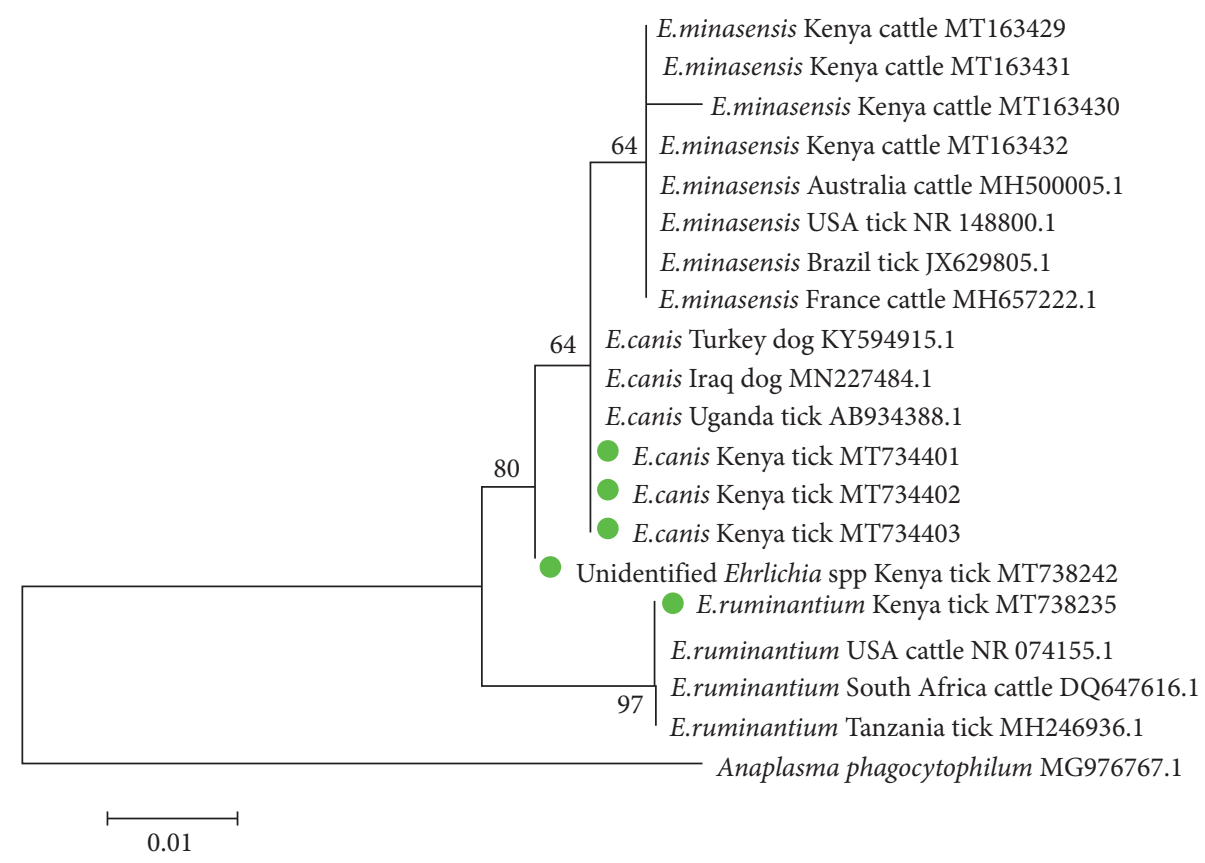

FIgURE 3: Maximum-likelihood tree of Ehrlichia spp. reconstructed based on partial sequences of $16 \mathrm{~S}$ rDNA gene with 1000 bootstrap replicates. The tree is drawn to scale, with branch lengths measured in the number of substitutions per site. The analysis involved 20 nucleotide sequences with five tick isolates (green dots) from this study and the other fifteen obtained from the GenBank. The tree indicates the phylogenetic relatedness of Ehrlichia isolates from ticks infesting cattle in peri-urban areas of Nairobi, Kenya, marked with green dots and sequences from other countries. Anaplasma phagocytophilum was used as an out-group. Sequence accession numbers are indicated at the end of each isolate.

genera consist of important species that transmit diseases of great economic impact to livestock production as well those of concern to human health [21].

The African blue tick (Rhipicephalus (boophilus) decoloratus) was the most prevalent tick species identified in the study cattle. This tick is the most widespread one host tick in Eastern, Central, and Southern Africa [37, 38]; therefore, these results were not surprising. It is known to transmit Babesia bigemina [39] and Anaplasma marginale [40], which are endemic pathogens in the study area [28]. Indeed, A. marginale was detected in the sampled cattle from where the ticks were collected [18].

The Asian blue tick (Rh. (boophilus) microplus) was also identified in the study cattle. This tick was first reported in the coastal areas of Kenya by Hoogstraal and Walker [41], and since then, no reports of this tick have been made until recently when Kanduma et al. [12] characterized this tick in Kwale County using molecular markers. These tick species are highly invasive and have been reported to replace $R h$. (boophilus) decoloratus in areas where both tick species exist $[42,43]$. They are most economically important in the subgenera boophilus due to their role in the transmission of fatal Babesia bovis infection [44] and the novel E. minasensis [45]. The identification of this tick species in other parts of the country implies the possible emergence of infections in areas that had no previous reports. In fact, Adjou Moumouni et al. [46] and Peter et al. [18] reported the presence of $B$. bovis and E. minasensis for the first time in cattle in periurban areas of Nairobi, respectively, suggesting the possible presence of the vector tick Rh. boophilus microplus as reported in this study. Uncontrolled animal movement in Kenya [7] and continued climate change have been suggested to be the key drivers in the spread of different tick species [47].

In this study, the brown dog tick (Rhipicephalus sanguineus), which typically infests dogs, was found infesting the cattle. The majority of the farms where the cattle were sampled were observed to keep dogs, possibly explaining the presence of these ticks. This may result in infection of cattle with dog-related pathogens such as Anaplasma platys as observed previously in the study cattle [18] and reported in other parts of the world $[48,49]$. Rhipicephalus sanguineus was also found to harbour unidentified Ehrlichia species, which clustered in a different clade from E. canis, which is the pathogen that $R h$. sanguineus is known to vector $[50,51]$. Whole-genome sequencing of this unknown Ehrlichia pathogen would shed light on its identity, and studies on its pathogenicity on cattle and the role of Rh. sanguineus in its transmission are needed.

Anaplasma ovis, the causative agent of ovine anaplasmosis, was detected in one Rhipicephalus evertsi evertsi attached to cattle similar to the report by Berggoetz et al. [52]. Although this pathogen is commonly isolated in small ruminants [53], the sharing of hosts by the different tick species may enable ticks to acquire multiple pathogens from different blood meals [54]. The detection of these pathogens in the ticks does not always imply vector competence $[6,55]$, but mechanical transmission may occur when susceptible hosts such as cattle come in contact with infected ticks [54]. 
Amblyomma variegatum and A. gemma were identified in this study. Amblyomma species are among the most important tick species in Africa transmitting devastating animal diseases such as heartwater disease $[43,56]$. These tick species have previously been identified and reported in Kenya $[10,33]$. Rickettsia conorii was detected in A. variegatum ticks as previously reported from a study by Mutai et al. [38] in Kenya. Although Ri. conorii has been detected frequently in $R h$. sanguineus, which is the documented vector tick $[57,58]$, it can also be detected in other tick species [59]. Amblyomma species have been known as the major reservoirs for the DNA of Rickettsia in Africa [60], and hence, it was not surprising to detect this pathogen in these ticks. The high attraction of Amblyomma ticks to humans [1] increases the risk of human infection by this pathogen.

In this study, Amblyomma variegatum was also found to harbour E. canis and E. ruminantium and in two cases coinfected with the DNA of Rickettsia spp. It was not surprising to detect E. ruminantium in A. variegatum ticks since they are the documented competent vectors for this pathogen [61, 62] and have previously been reported in Kenya [63]. Since A. variegatum has strongly been implicated in the transmission of Rickettsia species [64, 65], the detection of both Rickettsia species and E. ruminantium is possible [66]. The aggressive feeding habit by this tick species on various hosts [10] may explain the detection in the tick of E. canis, which is a pathogen of dog, and the coinfection reported in this study.

Hyalomma rufipes and Hyalomma truncatum were also identified in this study. These tick species have been reported previously in various parts of Kenya [33, 56, 63]. Rickettsia aeschlimannii was detected in Hyalomma rufipes ticks in this study. Hyalomma species are the documented vectors for Ri. aeschlimannii [60]. This pathogen was first detected and characterized in Hyalomma marginatum in Morocco [67], and since then, it has been isolated in different species of Hyalomma ticks in Kenya [9, 63], Ethiopia and Chad [68], Senegal [59], and Europe [69, 70]. Additionally, Ri. aeschlimannii was also detected in Rh. microplus tick. The detection of this pathogen in Rh. (boophilus) microplus is not surprising since Mutai et al. [38] and Reye et al. [54] detected this pathogen in its closely related species of $R h$. (boophilus) annulatus attached to cattle from Kenya and Nigeria, respectively. Moreover, Pretorius and Birtles [71] also identified $R i$. aeschlimannii in Rh. appendiculatus tick from South Africa. This indicates that Ri. aeschlimannii can be found in many other tick species although the vector competence for these tick species needs to be evaluated.

Although vector competence for some of the tick species found carrying pathogens identified in this study is yet to be established, their recognition in these ticks expands the knowledge on pathogens harboured by ticks infesting dairy cattle in peri-urban areas of Nairobi. The surveillance of pathogens in ticks has been viewed as a good start to preempt pathogens that could potentially infect animals and people [19]. Additionally, the identification of tick species and the detection of the pathogens they harbour in various areas of a country have been viewed as a prerequisite for developing appropriate tick control programs during targeted tick control [2].
In this study, Ri. conorii and Ri. aeschlimannii, which are zoonotic pathogens, were detected in ticks infesting cattle. Rickettsia conorii has been associated with febrile disease causing severe morbidity [72] and even fatality in tourists returning from Kenya [73], while Ri. aeschlimannii, which is a closely related pathogen, manifests with a mild disease [74]. Infection of humans with rickettsiosis occurs from contact with domestic animals or pets that act as reservoir host from which tick bites occur [54]. Indeed, Thiga et al. [75] reported a higher seroprevalence and titers of spotted fever group (SFG) rickettsiosis among pastoralists keeping large numbers of livestock than other communities in Kenya. The febrile disease from rickettsiosis has been commonly confused for malaria and typhoid, especially in Africa including Kenya where these diseases are endemic $[76,77]$. In Kenya, there is evidence that rickettsiosis contributes to a great percentage of febrile cases reported in hospitals [78].

Since ticks remain infected with rickettsiosis for life while transmitting transstadially and transovarially [58], a public health risk is posed by their detection in ticks $[54,74]$. Additionally, since dogs and ruminants are the implicated domestic reservoirs for this rickettsiosis [79], a country-wide surveillance to understand the status of the domestic reservoirs would be informative. Additionally, further characterization of the Rickettsia species and strains found in ticks and cattle using more specific primers targeting outer membrane proteins (Omp A and $\mathrm{OmpB}$ ), citrate synthase, and $17 \mathrm{kDa}$ proteins $[80,81]$ is necessary.

The 16S rDNA gene was used to infer phylogenetics of pathogens detected in the ticks from this study. Rickettsia species have a highly conserved genome, and their mitochondrial 16S rDNA has been previously used to detect tick microbiome [82-84]. Rickettsia conorii detected in this study showed high diversity and were closely related to an isolate from Nigeria, the USA, and China but differed from those from Uganda and Zambia. This indicates that different variants of the Rickettsia may exist in the study area with some that may be unique to Kenya. E. canis isolates were highly conserved and similar to those isolated from Turkey, Iraq, and neighboring Uganda, a suggestion that the strains may be similar to those isolated worldwide and their introduction may be associated with the international pet movement, which has been associated with pathogen spread [85].

The limitation of this study was that it was carried out during the dry season, therefore may not provide the whole spectrum of the tick species and the associated pathogens that would be expected in the study area. Future studies covering both the dry and wet seasons would provide a greater diversity of the ticks and their pathogens in these peri-urban areas.

\section{Conclusion}

Dairy cattle in peri-urban areas of Nairobi, Kenya, were infested with different tick species in the genera Rhipicephalus, Amblyomma, and Hyalomma. The ticks harboured DNA of various Ehrlichia species including the dog- 
associated Ehrlichia canis and zoonotic Rickettsia pathogens. This highlights the animal health threat and public health concern posed by the infestation of these ticks on the dairy cattle. Therefore, effective tick control remains paramount for the control of these pathogens. The role of cattle as alternative hosts for the dog-associated pathogens such as E. canis detected in ticks infesting cattle needs to be investigated, especially when cattle are in close proximity to the dogs. There is a need for molecular characterization of the identified tick species using specific genes such as interspacer (ITS) and CO1 genes to confirm the presence of the emerging invasive $R h$. microplus ticks in various counties in Kenya.

\section{Data Availability}

The data used in this manuscript are available from the corresponding author on request. The DNA sequence of the pathogens analysed is available on GenBank using the accession numbers indicated in this manuscript.

\section{Disclosure}

This manuscript is part of a $\mathrm{PhD}$ thesis that has been previously published [86] by the first author.

\section{Conflicts of Interest}

The authors declare that they have no conflict of interest.

\section{Authors' Contributions}

SGP, HWK, GOA, DWG, NM, and CMM designed the study; SGP and DWG collected the data; and SGP, HWK, and NM analysed the data. All the authors were involved in the drafting, reading, and approval of the final submission of the manuscript.

\section{Acknowledgments}

The authors appreciate the laboratory support from $\mathrm{Mr}$. Richard Omulo Otieno during tick identification and Mr. Alfred Mainga in the molecular laboratory. The authors express their sincere gratitude to the farmers from Westlands, Dagoretti, Lang'ata, and Kasarani subcounties of Nairobi County who consented to their animals being included in this study. This research was supported by the Consortium for Advanced Research Training in Africa (CARTA). CARTA is jointly led by the African Population and Health Research Center and the University of the Witwatersrand and funded by the Carnegie Corporation of New York (Grant No. B 8606.R02), Sida (Grant No. 54100113), the DELTAS Africa Initiative (Grant No. 107768/ $\mathrm{Z} / 15 / \mathrm{Z}$ ), and Deutscher Akademischer Austauschdienst (DAAD). The DELTAS Africa Initiative is an independent funding scheme of the African Academy of Sciences (AAS)'s Alliance for Accelerating Excellence in Science in Africa (AESA) and supported by the New Partnership for Africa's Development Planning and Coordinating Agency (NEPAD Agency) with funding from the Wellcome Trust (UK) and the UK Government. The statements made and views expressed are solely the responsibility of the fellow.

\section{References}

[1] P. Parola and D. Raoult, "Ticks and tickborne bacterial diseases in humans: an emerging infectious threat," Clinical Infectious Diseases, vol. 32, no. 6, pp. 897-928, 2001.

[2] Z. I. Rajput, S.-h. Hu, W.-j. Chen, A. G. Arijo, and C.-w. Xiao, "Importance of ticks and their chemical and immunological control in livestock," Journal of Zhejiang University-Science B, vol. 7, no. 11, pp. 912-921, 2006.

[3] Y. Rikihisa, "Anaplasma phagocytophilum and Ehrlichia chaffeensis: subversive manipulators of host cells," Nature Reviews Microbiology, vol. 8, no. 5, pp. 328-339, 2010.

[4] S. Wikel, "Ticks and tick-borne infections: complex ecology, agents, and host interactions," Veterinary Sciences, vol. 5, no. 2, p. 60, 2018.

[5] K. P. Shyma, J. P. Gupta, and V. Singh, "Breeding strategies for tick resistance in tropical cattle: a sustainable approach for tick control," Journal of Parasitic Diseases, vol. 39, no. 1, pp. 1-6, 2013.

[6] B. Doudier, J. Olano, P. Parola, and P. Brouqui, "Factors contributing to emergence of Ehrlichia and Anaplasma spp. as human pathogens," Veterinary Parasitology, vol. 167, no. 2-4, pp. 149-154, 2010.

[7] F. Keesing, R. S. Ostfeld, T. P. Young, and B. F. Allan, "Cattle and rainfall affect tick abundance in central Kenya," Parasitology, vol. 145, no. 3, pp. 345-354, 2018.

[8] C. J. Rademaker, B. Omedo Bebe, J. van der Lee, C. Kilelu, and C. Tonui, "Sustainable growth of the Kenyan dairy sector: a quick scan of robustness, reliability and resilience," Report 3RKenya/WLR 979, Wageningen Livestock Research, Wageningen, Netherlands, 2016.

[9] H. Koka, R. Sang, H. L. Kutima, L. Musila, and K. Macaluso, "The detection of spotted fever group rickettsia DNA in tick samples from pastoral communities in Kenya," Journal of Medical Entomology, vol. 54, pp. 774-780, 2017.

[10] M. Oswe, R. Odhiambo, B. Mutai, N. Nyakoe, G. Awinda, and J. N. Waitumbi, "Zoonotic pathogens in ticks collected from livestock in Kenya," Open Journal of Preventive Medicine, vol. 08, no. 08, pp. 248-259, 2018.

[11] M. M. Mwamuye, E. Kariuki, D. Omondi et al., "Novel Rickettsia and emergent tick-borne pathogens: a molecular survey of ticks and tick-borne pathogens in Shimba Hills National Reserve, Kenya," Ticks and Tick-borne Diseases, vol. 8, no. 2, pp. 208-218, 2017.

[12] E. G. Kanduma, D. Emery, N. W. Githaka, E. K. Nguu, R. P. Bishop, and J. Šlapeta, "Molecular evidence confirms occurrence of Rhipicephalus (Boophilus) microplus in Kenya and suggests that an undifferentiated genotype is prevalent in the African continent," Parasites \& Vectors, 2020.

[13] Kenya National Bureau of Statistics, "2019 Kenya population and housing census volume 1: population by county and subcounty," 2019, https://www.knbs.or.ke/?wpdmpro=2019kenya-population-and-housing-census-volume-i-populationby-county-and-sub-county.

[14] J. Nguhiu-Mwangi, J. W. Aleri, E. G. Mogoa, and P. M. F. Mbithi, Indicators of Poor Welfare in Dairy Cows within Smallholder Zero-Grazing Units in the Peri-Urban Areas of Nairobi, Kenya, pp. 50-87, InTech, London, 2013, Insights from Veterinary Medicine.

[15] J. W. Aleri, J. Nguhiu-Mwangi, E. M. Mogoa, and C. M. Mulei, "Welfare of dairy cattle in the smallholder (zero-grazing) 
production systems in Nairobi and its environs," Livestock Research for Rural Development, vol. 24, p. 8, 2012.

[16] P. Alarcon, E. M. Fèvre, P. Muinde et al., "Urban livestock keeping in the city of Nairobi: diversity of production systems, supply chains, and their disease management and risks," Frontiers in Veterinary Science, vol. 4, p. 171, 2017.

[17] F. Garry, Miscellaneous Infectious Diseases, pp. 606-639, W.B. Saunders, Philadelphia, PA, USA, 2008, Rebhun's Diseases of Dairy Cattle.

[18] S. G. Peter, G. O. Aboge, H. W. Kariuki et al., "Molecular prevalence of emerging Anaplasma and Ehrlichia pathogens in apparently healthy dairy cattle in peri-urban Nairobi, Kenya," BMC Veterinary Research, vol. 16, no. 1, p. 364, 2020.

[19] Y. Qiu, R. Nakao, A. Ohnuma, F. Kawamori, and C. Sugimoto, "Microbial population analysis of the salivary glands of ticks; a possible strategy for the surveillance of bacterial pathogens," PLoS One, vol. 9, pp. 1-11, Article ID 0103961, 2014.

[20] S. G. Peter, D. W. Gakuya, N. Maingi, and C. M. Mulei, "Prevalence and risk factors associated with Ehrlichia infections in smallholder dairy cattle in Nairobi City County, Kenya," October-2019, vol. 12, no. 10, pp. 1599-1607, 2019.

[21] A. R. Walker, A. Bouattour, J.-L. Camicas et al., Ticks of Domestic Animals in Africa: A Guide to Identification of Species, Bioscience Reports, Edinburgh Scotland, UK, 2nd edition, 2014.

[22] C. Silaghi, A. S. Santos, J. Gomes et al., "Guidelines for the direct detection of Anaplasma spp. in diagnosis and epidemiological studies," Vector Borne and Zoonotic Diseases, vol. 17, no. 1, pp. 12-22, 2017.

[23] R. C. Edgar, "Local homology recognition and distance measures in linear time using compressed amino acid alphabets," Nucleic Acids Research, vol. 32, no. 1, pp. 380-385, 2004.

[24] F. Madeira, Y. m. Park, J. Lee et al., "The EMBL-EBI search and sequence analysis tools APIs in 2019," Nucleic Acids Research, vol. 47, no. W1, pp. W636-W641, 2019.

[25] K. Tamura, G. Stecher, D. Peterson, A. Filipski, and S. Kumar, "MEGA6: molecular evolutionary genetics analysis version 6.0," Molecular Biology and Evolution, vol. 30, no. 12, pp. 2725-2729, 2013.

[26] K. Tamura and M. Nei, "Estimation of the number of nucleotide substitutions in the control region of mitochondrial DNA in humans and chimpanzees," Molecular Biology and Evolution, vol. 10, pp. 512-526, 1993.

[27] J. Felsenstein, "Confidence limits on phylogenies: an Approach using the Bootstrap," Evolution, vol. 39, no. 4, pp. 783-791, 1985.

[28] D. W. Gakuya and C. M. Mulei, "An investigation of the incidences of East Coast Fever (ECF), Anaplasmosis and Babesiosis in the bovine cases managed by ambulatory services of the faculty of veterinary medicine, Kabete," The Kenya Veterinarian, vol. 29, pp. 21-24, 2005.

[29] D. Mureithi and E. Mukiria, "An assessment of tick-borne diseases constraints to livestock production in a smallholder livestock production system: a case of njiru district, Kenya," International Journal of Research in Agriculture and Forestry, vol. 2, pp. 43-49, 2015.

[30] S. W. Chenyambuga, C. Waiswa, M. Saimo, P. Ngumi, and P. S. Gwakisa, "Knowledge and perceptions of traditional livestock keepers on tick-borne diseases and sero-prevalence of Theileria parva around Lake Victoria Basin," Livestock Research for Rural Development, vol. 22, 2010.

[31] J. M. Mugambi, F. D. Wesonga, and S. G. Ndungu, “Ticks and tick-borne disease control in a pastoral and an agro-pastoral farming systems in Kenya," Livestock Research for Rural Development, vol. 24, 2012.

[32] D. Mureithi and E. Mukiria, "An assessment of tick-borne diseases constraints to livestock production in a smallholder livestock production system: a case of njiru district , Kenya," Livestock Research for Rural Development, vol. 22, pp. 43-49, 2010.

[33] E. K. Kariuki, B. L. Penzhorn, and I. G. Horak, “Ticks (Acari: ixodidae) infesting cattle and African buffaloes in the Tsavo conservation area, Kenya," Onderstepoort Journal of Veterinary Research, vol. 79, pp. E1-E4, 2012.

[34] E. S. Swai, P. F. Mtui, A. K. Chang'a, and G. E. Machange, "The prevalence of serum antibodies to Ehrlichia ruminantium infection in ranch cattle in Tanzania: a cross-sectional study," Journal of the South African Veterinary Association, vol. 79, no. 2, pp. 71-75, 2008.

[35] C. Byaruhanga, N. E. Collins, D. Knobel, W. Kabasa, and M. C. Oosthuizen, "Endemic status of tick-borne infections and tick species diversity among transhumant zebu cattle in Karamoja Region, Uganda: support for control approaches," Veterinary Parasitology: Regional Studies and Reports, vol. 1-2, no. 2, pp. 21-30, 2015.

[36] K. Mideksa, G. Haile, N. Mekonnen, and W. Furgasa, "Prevalence and identification of bovine ixodide tick in dandi district, west shoa zone, oromia region, Ethiopia," SOJ Veterinary Sciences, vol. 3, pp. 1-8, 2017.

[37] C. Byaruhanga, Epidemiology and Tick-Borne Haemoparasite Diversity Amongst Transhumant Zebu Cattle in Karamoja Region, Uganda, University of Pretoria, Pretoria, South Africa, 2017.

[38] B. K. Mutai, J. M. Wainaina, C. G. Magiri et al., "Zoonotic surveillance for rickettsiae in domestic animals in Kenya," Vector Borne and Zoonotic Diseases, vol. 13, no. 6, pp. 360366, 2013.

[39] R. Bock, L. Jackson, A. De Vos, and W. Jorgensen, "Babesiosis of cattle," Parasitology, vol. 129, no. S1, pp. S247-S269, 2004.

[40] K. M. Kocan, J. De La Fuente, E. F. Blouin, and J. C. GarciaGarcia, "Anaplasma marginale (Rickettsiales: anaplasmataceae): recent advances in defining host-pathogen adaptations of a tick-borne rickettsia," Parasitology, vol. 129, no. S1, pp. S285-S300, 2004.

[41] H. Hoogstraal and J. B. Walker, "The ixodid ticks of Kenya. A review of present knowledge of their hosts and distribution," The Journal of Parasitology, vol. 61, p. 694, 1974.

[42] D. Muhanguzi, J. Byaruhanga, W. Amanyire et al., "Invasive cattle ticks in East Africa: morphological and molecular confirmation of the presence of Rhipicephalus microplus in south-eastern Uganda," Parasites \& Vectors, vol. 13, pp. 165-169, 2020.

[43] B. A. Silatsa, G. Simo, N. Githaka et al., "A comprehensive survey of the prevalence and spatial distribution of ticks infesting cattle in different agro-ecological zones of Cameroon," Parasites \& Vectors, vol. 12, pp. 489-514, 2019.

[44] M. C. S. Oliveira, T. C. G. Oliveira-Sequeira, L. C. A. Regitano et al., "Detection of Babesia bigemina in cattle of different genetic groups and in Rhipicephalus (Boophilus) microplus tick," Veterinary Parasitology, vol. 155, no. 3-4, pp. 281-286, 2008.

[45] I. T. S. Carvalho, A. L. T. Melo, L. C. Freitas et al., "Minimum infection rate of Ehrlichia minasensis in Rhipicephalus microplus and Amblyomma sculptum ticks in Brazil," Ticks and Tick-borne Diseases, vol. 7, no. 5, pp. 849-852, 2016.

[46] P. F. Adjou Moumouni, G. O. Aboge, M. A. Terkawi et al., "Molecular detection and characterization of Babesia bovis, 
Babesia bigemina, Theileria species and Anaplasma marginale isolated from cattle in Kenya," Parasites \& Vectors, vol. 8, pp. 1-14, 2015.

[47] N. Nyangiwe, A. Harrison, and I. G. Horak, "Displacement of rhipicephalus decoloratus by rhipicephalus microplus (Acari: ixodidae) in the eastern cape province, South Africa," Experimental \& Applied Acarology, vol. 61, no. 3, pp. 371-382, 2013.

[48] T. E. Hsi, S. W. Hsiao, N. T. Minahan et al., "Seroepidemiological and molecular investigation of spotted fever group rickettsiae and Coxiella burnetii in Sao Tome Island: a One Health approach," Transboundary and Emerging Diseases tbed, vol. 67, Article ID 13191, 2019.

[49] B. C. Iweriebor, E. J. Mmbaga, A. Adegborioye, A. Igwaran, L. C. Obi, and A. I. Okoh, "Genetic profiling for Anaplasma and Ehrlichia species in ticks collected in the eastern cape province of South Africa," BMC Microbiology, vol. 17, pp. 45-48, 2017.

[50] A. Bessas, H. Leulmi, I. Bitam et al., "Molecular evidence of vector-borne pathogens in dogs and cats and their ectoparasites in Algiers, Algeria," Comparative Immunology, Microbiology and Infectious Diseases, vol. 45, pp. 23-28, 2016.

[51] J. Moraes-Filho, F. S. Krawczak, F. B. Costa, J. F. Soares, and M. B. Labruna, "Comparative evaluation of the vector competence of four South American populations of the rhipicephalus sanguineus group for the bacterium Ehrlichia canis, the agent of canine monocytic ehrlichiosis," PLoS One, vol. 10, pp. 1-16, Article ID 0139386, 2015.

[52] M. Berggoetz, M. Schmid, D. Ston et al., "Protozoan and bacterial pathogens in tick salivary glands in wild and domestic animal environments in South Africa," Ticks and Tickborne Diseases, vol. 5, no. 2, pp. 176-185, 2014.

[53] M. Dahmani, J.-L. Marié, P. Scandola, S. Brah, B. Davoust, and O. Mediannikov, "Anaplasma ovis infects sheep in Niger," Small Ruminant Research, vol. 151, pp. 32-35, 2017.

[54] A. L. Reye, O. G. Arinola, J. M. Hübschen, and C. P. Muller, "Pathogen prevalence in ticks collected from the vegetation and livestock in Nigeria," Applied and Environmental Microbiology, vol. 78, no. 8, pp. 2562-2568, 2012.

[55] R. Sadeddine, A. Z. Diarra, M. Laroche et al., "Molecular identification of protozoal and bacterial organisms in domestic animals and their infesting ticks from north-eastern Algeria," Ticks and Tick-borne Diseases, vol. 11, no. 2, p. 101330, 2020.

[56] J. Lutomiah, L. Musila, A. Makio et al., "Ticks and tick-borne viruses from livestock hosts in arid and semiarid regions of the eastern and northeastern parts of Kenya," Journal of Medical Entomology, vol. 51, no. 1, pp. 269-277, 2014.

[57] M. Ionita, C. Silaghi, I. L. Mitrea, S. Edouard, P. Parola, and K. Pfister, "Molecular detection of Rickettsia conorii and other zoonotic spotted fever group rickettsiae in ticks, Romania," Ticks and Tick-borne Diseases, vol. 7, no. 1, pp. 150-153, 2016.

[58] D. Liu, "Rickettsia," in Molecular Medical Microbiology, pp. 2043-2056, Elsevier, Amsterdam, Netherlands, 2nd edition, 2014.

[59] O. Mediannikov, G. Diatta, F. Fenollar, C. Sokhna, J.-F. Trape, and D. Raoult, "Tick-borne rickettsioses, neglected emerging diseases in rural Senegal," PLoS Neglected Tropical Diseases, vol. 4, no. 9, Article ID e821, 2010.

[60] P. Parola, C. D. Paddock, C. Socolovschi et al., "Update on tick-borne rickettsioses around the world: a geographic approach," Clinical Microbiology Reviews, vol. 26, no. 4, pp. 657-702, 2013.
[61] S. Teshale, D. Geysen, G. Ameni, Y. Asfaw, and D. Berkvens, "Improved molecular detection of Ehrlichia and Anaplasma species applied to Amblyomma ticks collected from cattle and sheep in Ethiopia," Ticks and Tick-borne Diseases, vol. 6, no. 1, pp. 1-7, 2015.

[62] B. Faburay, D. Geysen, S. Munstermann, A. Taoufik, M. Postigo, and F. Jongejan, "Molecular detection of Ehrlichia ruminantium infection in Amblyomma variegatum ticks in the Gambia," Experimental \& Applied Acarology, vol. 42, no. 1, pp. 61-74, 2007.

[63] D. Omondi, D. K. Masiga, B. C. Fielding et al., "Molecular detection of tick-borne pathogen diversities in ticks from livestock and reptiles along the shores and adjacent islands of lake victoria and lake baringo, Kenya," Frontiers in Veterinary Science, vol. 4, pp. 73-15, 2017.

[64] V. Cicculli, X. de Lamballerie, R. Charrel, and A. Falchi, "First molecular detection of Rickettsia africae in a tropical bont tick, Amblyomma variegatum, collected in Corsica, France," Experimental \& Applied Acarology, vol. 77, no. 2, pp. 207-214, 2019.

[65] V. Lorusso, K. A. Gruszka, A. Majekodunmi, A. Igweh, S. C. Welburn, and K. Picozzi, "Rickettsia africae in Amblyomma variegatum ticks, Uganda and Nigeria," Emerging Infectious Diseases, vol. 19, no. 10, pp. 1705-1707, 2013.

[66] J. B. Robinson, M. E. Eremeeva, P. E. Olson et al., "New approaches to detection and identification of Rickettsia africae and Ehrlichia ruminantium in Amblyomma variegatum (Acari: ixodidae) ticks from the caribbean," Journal of Medical Entomology, vol. 46, no. 4, pp. 942-951, 2009.

[67] L. Beati, M. Meskini, B. Thiers, and D. Raoult, "Rickettsia aeschlimannii sp. nov., a new spotted fever group Rickettsia associated with Hyalomma marginatum ticks," International Journal of Systematic Bacteriology, vol. 47, no. 2, pp. 548-554, 1997.

[68] A. Mura, C. Socolovschi, J. Ginesta et al., "Molecular detection of spotted fever group rickettsiae in ticks from Ethiopia and Chad," Transactions of The Royal Society of Tropical Medicine and Hygiene, vol. 102, no. 9, pp. 945-949, 2008.

[69] L. Chitimia-Dobler, S. Schaper, R. Rieß et al., "Imported Hyalomma ticks in Germany in 2018," Parasites \& Vectors, vol. 12, no. 1, p. 134, 2019.

[70] G. G. Duscher, A. Hodžić, P. Hufnagl et al., "Adult Hyalomma marginatum tick positive for Rickettsia aeschlimannii in Austria," Euro Surveillance, vol. 23, Article ID 1800595, 2018.

[71] A. M. Pretorius and R. J. Birtles, "Rickettsia aeschlimannii: a new pathogenic spotted fever group Rickettsia, South Africa," Emerging Infectious Diseases, vol. 8, p. 874, 2002.

[72] H. Yoshikawa, M. Ogawa, M. Kimura, D. Raoult, and J.-M. Rolain, "Laboratory-confirmed mediterranean spotted fever in a Japanese traveler to Kenya," The American Journal of Tropical Medicine and Hygiene, vol. 73, no. 6, pp. 1086-1089, 2005.

[73] J. S. Rutherford, K. Macaluso, N. Smith et al., "Fatal spotted fever rickettsiosis, Kenya," Emerging Infectious Diseases, vol. 10, no. 5, pp. 910-913, 2004.

[74] D. Raoult, P.-E. Fournier, P. Abboud, and F. Caron, "First documented human Rickettsia aeschlimannii infection [2]," Emerging Infectious Diseases, vol. 8, no. 7, pp. 748-749, 2002.

[75] J. W. Thiga, B. K. Mutai, W. K. Eyako et al., "High seroprevalence of antibodies against spotted fever and scrub typhus bacteria in patients with febrile illness, Kenya," Emerging Infectious Diseases, vol. 21, no. 4, pp. 688-691, 2015. 
[76] A. N. Maina, C. M. Farris, A. Odhiambo et al., "Q fever, scrub typhus, and rickettsial diseases in children, Kenya, 2011-2012," Emerging Infectious Diseases, vol. 22, pp. 2011-2012, 2016.

[77] J. A. Crump, A. B. Morrissey, W. L. Nicholson et al., "Etiology of severe non-malaria febrile illness in northern Tanzania: a prospective cohort study," PLoS Neglected Tropical Diseases, vol. 7, no. 7, Article ID e2324, 2013.

[78] A. N. Maina, D. L. Knobel, J. Jiang et al., "Rickettsia felis infection in febrile patients, western Kenya, 2007-2010," Emerging Infectious Diseases, vol. 18, no. 2, pp. 328-331, 2012.

[79] P. Parola and D. Raoult, "Tropical rickettsioses," Clinics in Dermatology, vol. 24, no. 3, pp. 191-200, 2006.

[80] P. Parola, C. D. Paddock, and D. Raoult, "Tick-borne rickettsioses around the world: emerging diseases challenging old concepts tick-borne rickettsioses around the world: emerging diseases challenging old concepts," Clinical Microbiology Reviews, vol. 18, no. 4, pp. 719-756, 2005.

[81] D. H. Walker, "Rickettsiae and rickettsial infections: the current state of knowledge," Clinical Infectious Diseases, vol. 45, no. Supplement_1, pp. S39-S44, 2007.

[82] M. Buysse and O. Duron, "Two novel Rickettsia species of soft ticks in North Africa: 'Candidatus Rickettsia africaseptentrionalis' and 'Candidatus Rickettsia mauretanica,' Ticks and Tick-borne Diseases, vol. 11, no. 3, Article ID 101376, 2020.

[83] S. J. Dergousoff, C. A. Anstead, and N. B. Chilton, "Identification of bacteria in the Rocky Mountain wood tick, Dermacentor andersoni, using single-strand conformation polymorphism (SSCP) and DNA sequencing," Experimental \& Applied Acarology, vol. 80, no. 2, pp. 247-256, 2020.

[84] Y. S. Kim, J. Kim, Y. J. Choi, H. J. Park, and W. J. Jang, "Molecular genetic analysis and clinical characterization of Rickettsia species isolated from the Republic of Korea in 2017," Transboundary and Emerging Diseases, vol. 67, no. 4, pp. 1447-1452, 2020.

[85] N. N. Livanova, N. V. Fomenko, I. A. Akimov et al., "Dog survey in Russian veterinary hospitals: tick identification and molecular detection of tick-borne pathogens," Parasites \& Vectors, vol. 11, no. 1, p. 591, 2018.

[86] S. G. Peter, Epidemiology and Molecular Characterization of Anaplasma and Ehrlichia Species Infecting Dairy Cattle in Smallholder Farms in Peri-Urban Nairobi, Kenya, Ph.D. thesis, University of Nairobi, Nairobi, Kenya, 2020. 